\title{
The Ethical Triage and Management Guidelines of the Entrapped and Mangled Extremity in Resource Scarce Environments: A Systematic Literature Review
}

\author{
Eric Weinstein, MD, MScDM; James E. Gosney, MD, MPH; Luca Ragazzoni, MD, PhD; \\ Jeffrey Franc, MD, FCFP.EM; TeriLynn Herbert, MS, MLIS; Brielle Weinstein, PGY4; \\ Manuela Verde, MD, MScDM; Johannes Zeller, MD, MScDM; Nikolaj Wolfson, MD; \\ Will Boyce, MS4; Jordan Cramer, MS3
}

\section{ABSTRACT}

Objective: A systematic literature review (SLR) was performed to elucidate the current triage and treatment of an entrapped or mangled extremity in resource scarce environments (RSEs).

Methods: A lead researcher followed the search strategy following inclusion and exclusion criteria. A first reviewer (FR) was randomly assigned sources. One of the 2 lead researchers was the second reviewer (SR). Each determined the level of evidence (LOE) and quality of evidence (QE) from each source. Any differing opinions between the FR and SR were discussed between them, and if differing opinions remained, then a third reviewer (the other lead researcher) discussed the article until a consensus was reached. The final opinion of each article was entered for analysis.

Results: Fifty-eight (58) articles were entered into the final study. There was 1 study determined to be LOE 1, 29 LOE 2, and 28 LOE 3, with 15 determined to achieve QE 1, 37 QE 2, and 6 QE 3.

Conclusion: This SLR showed that there is a lack of studies producing strong evidence to support the triage and treatment of the mangled extremity in RSE. Therefore, a Delphi process is suggested to adapt and modify current civilian and military triage and treatment guidelines to the RSE.

Key Words: blast injuries, crush syndrome, delivery of health care, mass casualty incidents, standard of care

\section{INTRODUCTION}

While there are accepted triage and treatment guidelines for the entrapped and mangled extremity in civilian and military resource rich environments (RRE), there are none for resource scarce environments (RSE).

In 2002, Feliciano and the American College of Surgeons Committee on Trauma Subcommittee on Publications published the Management of the Mangled Extremity. ${ }^{1}$ This was not intended to "be comprehensive nor a standard of care" given the unique patient presentations in which the guidelines may be used. ${ }^{1}$ The definition of the mangled extremity is applicable regardless of setting, though the causes may be different with different high-energy transfer in the varied RSE. The injury patterns of military gunshot wounds are more devastating than the close-range shotgun wounds encountered in civilian environments. Similarly, blast injuries were rarely encountered in civilian environments as terror attacks have increased over time. The decisions for the treatment team remain, without altering standard of care in an RSE. ${ }^{2}$
In 2012, the Western Trauma Association (WTA) created a treatment algorithm "Management of the Mangled Extremity" placing persistent hemorrhage or refractory hemodynamic instability as the second decision to make after control of active hemorrhage. ${ }^{3}$ The majority of RSE settings will not have the opportunity to use computed tomography angiography imaging nor have the surgical staff with sufficient training and supplies to place an intraluminal shunt.

A systematic literature review (SLR) was performed to elucidate the current triage and treatment of an entrapped or mangled extremity in resource scarce (civilian and military) environments. Further analysis as a component of this practice was to understand the factors contributing to the decision to amputate or not amputate, to determine the incorporation of rehabilitation and social services, and the informed consent process.

Based on these studies, 49 data points could be considered for consensus ethical triage and treatment guidelines of the entrapped and mangled extremity. The 


\section{TABLE 1}

\section{Search Strategy}

Entrapped or mangled extremity or resource constrained or resource scarce or resource limited or critical environment conditions or mass casualty

and

Disaster or explosion or blast or terrorism or gunshot or ballistics or building collapse or crash or war or military or earthquake or tsunami or hurricane or cyclone or avalanche or flood

and

Amputation or damage control surgery or crush injuries or fracture or wound infection or fasciotomy or compartment syndrome or mangled extremity scoring system

and

Rehabilitation or prosthesis or orthotics or community integration or ethics or informed consent

RSE presents unique challenges to evaluate and treat a mangled extremity, specifically without evidence-based assessment and treatment guidelines. This SLR can begin the process of adapting and modifying current civilian and military guidelines to the RSE.

\section{METHODS}

English language studies published between January 1985 and March 2017 were retrieved for inclusion in agreement with the Preferred Reporting Items for Systematic Reviews and Meta-Analyses (PRISMA) Statement. The search strategy was designed to capture data reporting in an RSE: after a sudden-onset disaster, in a complex humanitarian emergency, in a conflict area, in a low-to-middle income country, or with long transport times. Unique criteria considered included those specific to certain mechanisms of injury, subsequent procedures, and those data points used in validated mangled extremity evaluation and treatment scoring systems. These points were sought to maintain a consistent approach comparing environments under the direction of an experienced Informationist $(\mathrm{TH})$ to comply with the PRISMA guidelines ${ }^{4}$ (Table 1). The databases were selected to ensure a comprehensive cull of available publications; references of selected articles were retrieved and considered in this SLR (Table 2).

ManageMe LLC (Toms River, NJ) was contracted to develop the data extraction tool combining evidence-based practice strategy, as well as content data. This Excel spreadsheet construct featured dropdowns to sort information for that specific question or to guide the reviewer to the next step. The initial section contained the demographics of the article and characteristics of article type, followed by inclusion and exclusion criteria (Table 3). The next section included data points to assist the reviewer in answering the question, "Does this evidence address my evidence-based practice question, to determine triage and treatment guidelines of the entrapped and mangled extremity in resource scarce environments?"
TABLE 2

\section{Database Searched}

\section{CINAHL Complete}

Disaster Lit. from DIMRC

and DTIC

DynaMed

Google Scholar

LILACS
National Guidelines Clearinghouse

PsycINFO

PubMed

Scopus

UpToDate

\section{TABLE 3}

\begin{tabular}{|c|c|}
\hline \multicolumn{2}{|c|}{ Criteria for Study Inclusion and Exclusion } \\
\hline Inclusion & Exclusion \\
\hline Meet research strategy & $\begin{array}{l}\text { Unverified, unsubstantiated press } \\
\text { or news media reports }\end{array}$ \\
\hline English language studies & $\begin{array}{l}\text { Not related to patient injured in a } \\
\text { sudden onset }\end{array}$ \\
\hline \multirow{2}{*}{$\begin{array}{l}\text { Between January } 1985 \text { and } \\
\text { March } 2017\end{array}$} & Abstracts without complete article \\
\hline & $\begin{array}{l}\text { Disaster, mass casualty incident, or } \\
\text { trauma }\end{array}$ \\
\hline
\end{tabular}

The 2 lead researchers (EW, JG) divided the articles that met inclusion criteria into 6 randomly assigned groups by a single 6 -sided dice roll. EndNoteX8 was used to collect the references and articles. A reviewer trained in this SLR process and a lead researcher were paired and assigned to each group to provide 2 independent reviews of level of evidence (LOE), quality of evidence $(\mathrm{QE})$, and data points for each article.

The LOE data points were acquired with opportunities for the reviewer to note specific findings that would aid the creation of a triage and treatment guideline based on the SLR (Table 4). Then the QE was ranked by "high (1) - good (2) - low (3)" by the reviewers. These sections featured the Johns Hopkins Nursing Evidence-Based Practice Research and Non-Research Evidence Appraisal questions for their ease of use and understanding ${ }^{5}$ (Table 5). The widely accepted Newcastle-Ottawa Quality Assessment Scale for case control and cohort studies was followed for these types of studies. ${ }^{6}$ In an effort to determine bias, the next sheet asked the reviewer to use the Cochrane Risk of Bias tool. ${ }^{7}$

Clinical data used in various triage and treatment guidelines were captured from an article's study of the entrapped and mangled extremity recording ${ }^{15}$ core clinical parameters that formed the basis of most studies (Table 6). Fourteen injuries and procedures were selected in order to compare similar studies (Table 7). The RSE radiology imaging presents a challenge to adopt or adapt triage and treatment guidelines from RRE escalating from plain imaging to fluoroscopy to assess bony injury and non-invasive Doppler/ultrasound to contrast angiography to assess vascular injury. The care setting discussed in each article was recorded for each RSE. The treatment of the 


\section{TABLE 4}

Level of Evidence ${ }^{\mathbf{5}}$
Level I
Experimental study, randomized controlled trial
(RCT), systematic review of RCTs, with or without
meta-analysis
Quasi-experimental study, systematic review of a
combination of RCTs and quasi-experimental, or
quasi-experimental studies only, with or without
meta-analysis
Level III
Level IV
Synthesis
Opinion of respected authorities and/or nationally
recognized expert committee/consensus panels
based on scientific evidence includes clinical
practice guidelines and consensus panels
Based on experiential and non-research evidence.
Includes literature review, quality improvement,
program or financial evaluation, case reports,
opinion of nationally recognized experts(s) based on
experiential evidence

\section{TABLE 5}

\section{Quality of Evidence ${ }^{5}$}

\section{A. High Quality}

B. Good Quality

C. Low Quality or Major Flaws

Consistent, generalizable results; sufficient sample size for the study design; adequate control; definitive conclusions; consistent recommendations based on comprehensive literature review that includes thorough references to scientific evidence

Reasonably consistent results; sufficient sample size for the study design; some control, fairly definitive conclusions; reasonably consistent recommendations based on fairly comprehensive literature review that includes some reference to scientific evidence

Little evidence with inconsistent results; insufficient sample size for the study design; conclusions cannot be drawn

mangled extremity includes rehabilitation services without altering the standard of care in an RSE. Data regarding prosthetics, orthotics, physical and occupational therapies, and community integration were sought to determine whether these were included in the reports. The other parameters noted involved ethics: informed consent; involvement of family, patient advocate, or community leader; and the religious or ethnic preference discussed.

A lead researcher (EW) received the 12 final data sheets (6 groups $\times 2$ reviewers each) to determine any data point
TABLE 6

\section{Clinical Parameters}

\section{Patient Age}

Shock: systemic hypotension, systemic circulation

Deep venous injury

Warm ischemia time: $4 \mathrm{hrs}, 6 \mathrm{hrs}$

Time since injury (hrs): 0-6, 6-12,

$<24,>24$

Wound contamination: minimal,

gross, NA

Periosteal stripping
Arterial injury

\section{Assessment Local Circulation}

Size of injury over fracture

Injury to skeletal structures: fracture $<50 \%$ circumference, $>50 \%$ comminution: without bone loss, with $<4 \mathrm{~cm},>4 \mathrm{~cm}$ bone loss

Assessment function

Assessment sensory nerve injury

Note comorbid conditions, concomitant injuries

Environmental factors (ie, weather, moisture, etc.)

\section{TABLE 7}

\section{Injury Pattern or Procedure}

\section{Entrapped Injury}

\section{Crush injury}

Length of time entrapped or

crush documented

Time entrapped or crushed

Traumatic amputation

Complete partial traumatic amputation

(with only skin bridge of non-viable

distal extremity)

Primary amputation

\section{Revision Primary Amputation} (damage control surgery)

Stump revision

Fasciotomy

Staged debridement

Closed reduction fracture

Open reduction internal

fixation

External fixation disagreement between the 2 assigned reviewers, specifically, the LOE because only LOE $1-3$ were included in the final analysis. Any disagreement was discussed amongst the 2 reviewers to reach consensus. If consensus was not met, then the lead researcher (EW or JG) who was not 1 of the 2 reviewers of that article was asked to arbitrate, discussing the article with the reviewers until a consensus was met. A third set of 6 data sheets was created reflecting consensus data and sent to ManageMe to concatenate the 6 sheets into 1. csv file to prepare for statistical analysis by MedStatStudio (Edmonton, Alberta, Canada).

The complete data extraction tool is available upon request.

This study was a literature review and did not involve human subjects and is registered PROSPERO 2017:CRD42017 052015.

\section{RESULTS}

\section{Summary of Literature Reviewed}

The initial total number of references obtained was 597, and, after removal of duplicates, abstracts, non-English, or other 
FIGURE 1

\section{PRISMA Flow.}
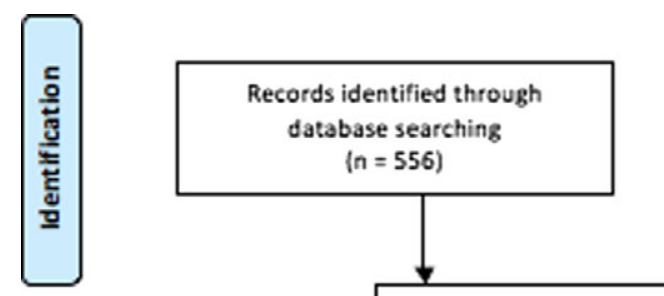

Additional records identified

through other sources

( $n=556$ )

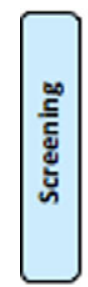

Records after duplicates removed

( $n=597$ )

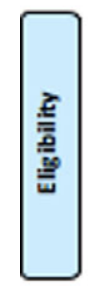

$(n=47)$

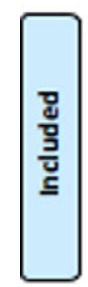

Studies included in

qualitative synthesis

$(n=58$ )

exclusion criteria, 297 were entered into the review process

(Figure 1).

Table 8 shows the 58 articles that were entered into the final SLR study, with 46 single studies, 11 multiple studies, and 21 with control groups. There was 1 study determined to be LOE $18,29 \operatorname{LOE} 2^{9-37}$, and $28 \operatorname{LOE} 3^{38-64}$, with 15 determined to achieve QE $1^{8,11,14,16,18,24,25,31,43,44,46,48,50,55,63,65}$, 37 QE $2^{9,10,12,13,15,17,19,21,26-30,32-42,47,49,51,52,56-62,64,66}$, and 6 QE $3^{20,22,23,45,53,54}$.

\section{Parameters (\#of Articles)}

The parameters were selected as general categories to assist the analysis of LOE and QE, not for detailed analysis of the individual clinical parameter, as this would be an entirely different SLR. The data are presented as the total number of articles (\# of articles) for the reader to appreciate the number of articles that the parameter is mentioned out of the selected total number of articles that met inclusion criteria.

\section{Clinical Parameters}

Fifteen clinical data points, including the time of injury (29), duration of ischemia (31), assessment of circulation (42), wound contamination (24), and limb function (25), were reported; standard fundamental history and physical data points should be included in the triage and treatment calculus of any injury in any environment. Similarly, documentation of clinical findings included in widely accepted mangled extremity scoring systems requires the reporting of an arterial (40), venous (30), nerve (42), or skeletal (37) injury. The Gustillo classification of open extremity fractures requires reporting if the injury was over a fracture (32) or involved periosteal stripping (24). (See Table 6.) 


\section{Level and Quality of Evidence Results}

$\begin{array}{lc}\text { Level of Evidence } & \text { Number of Studies } \\ 1 & 1 \\ 2 & 29 \\ 3 & 28 \\ \text { Quality of Evidence } & \\ 1 & 15 \\ 2 & 37 \\ 3 & 6\end{array}$

\section{Injury Patterns or Procedures}

There were only 9 articles from this SLR discussing the triage and treatment of the entrapped mangled extremity at the scene. Either at the scene or at definitive care, the general acceptance of converting a skin bridge, a near complete amputation with only a small portion of skin intact with complete neurovascular and bone destruction to a complete amputation, was noted in 16 articles. Specific operative procedures of primary amputation (47), staged debridement (33), damage control surgery (36), fasciotomy (24), closed reduction (12), internal fixation (15), external fixation (24), and stump revision (12) were collected. (See Table 7.)

\section{Imaging}

Studies with the ideal of angiography (16) and fluoroscopy (3) to the common plain (16) and increasingly RSE-viable non-invasive (15) modalities were noted.

\section{Medications}

There was reporting of general (27), local (4), and regional (3) anesthesia articles with 9 reporting analgesia and 26 reporting antibiotics.

\section{Clinical Setting}

In this SLR, the overwhelming majority of studies (53) were conducted in fixed medical facilities. There were studies from alternative care sites (9) such as tents, in the open air or non-medical structures and non-medical fixed structures (8) sources. Sources of studies came from Disaster Medical Assistance Teams (9), World Health Organization (WHO) Emergency Medical Teams (EMTs) (21), the WHO (20), non-WHO research centers (12) like Médecins Sans Frontières (MSF) and the International Committee of the Red Cross (ICRC), government organizations (GOs) (18), and nongovernment organizations (non-GOs) (10).

\section{Rehabilitation}

Data were recorded to learn whether specific aspects of the WHO Minimum Technical Standards and Recommendations for Rehabilitation were reported. ${ }^{67}$ This standard was referenced in this SLR with prosthetics (8), orthotics (9), occupational therapy (14), physical therapy (16), and community integration (11).

\section{Ethics}

Data were also recorded to learn whether the WHO Minimum Standards for (Foreign) EMTs regarding informed consent and ethical considerations was reported before and after this publication. ${ }^{68}$ This was mentioned in 8 articles with family (3), patient advocate or community leader (1) participating on behalf of or assisting the patient. Only 2 articles made specific mention of religious or ethnic preference that guided treatment of the entrapped and mangled extremity.

Final data sheets are available upon request.

\section{LIMITATIONS}

There may be consequential non-English articles that were beyond our collective capabilities. Despite our attempts to capture relevant articles through gray literature (non-scientific or non-peer-reviewed journals and lay press) and a process to "follow the breadcrumbs" (retrieving references cited in articles), there may have been relevant articles that were not secured.

This study ended in 2017 and was submitted for publication in 2019. It is possible that there were other published studies that could have influenced the results. The use of SLR tools to determine level, QE, risk of bias, case control, and cohort studies reflects what was available during the time frame of the SLR; in the end, the change between versions is debatable in the context of this SLR.

\section{DISCUSSION}

The publication of "The Management of Limb Injuries During Conflicts and Disasters" by the WHO EMT Secretariat, ICRC, and the AO Foundation in 2015 continued the discussion of triage and treatment of the entrapped or mangled extremity in Chapter 10, "Amputations." ${ }^{99}$ Their (WHO EMT) appeal for a multi-dimensional process as constructed in the WTA is based on lessons learned in Haiti after the 2010 earthquake. This SLR did find evidence that the general principles of definitive amputation espoused in this management publication were evident in line with the WTA that called for utilization of an intraluminal shunt. In the absence of vascular reconstructive capabilities, an amputation is indicated with an avascular limb. It becomes incumbent on the RSE treatment team to be aware of what reconstructive resources are at their disposal in the immediate, short, and long term to enhance the decision process to delay care toward limb salvage.

Jensen et al., in 2019, wrote that "the group (the authors) states that no amputation should be done immediately" yet this SLR did not find evidence to support this absolute statement when there are scenarios in a RSE that would place the patient's life in jeopardy. ${ }^{65}$ The timeline of injury to patient 
presentation in some RSEs is difficult to determine as patients may have to be extricated, transported, and then wait for initial and then definitive treatment. This timeline is of course needed to calculate whether the warm ischemia time or arterial occlusion is greater than 6 hours. ${ }^{54}$

More pressing is the determination of arterial insufficiency while the extremity is still entrapped as the rescue team does not know the status of the extremity on the other side of the entrapment unless structural assessment can conclusively determine otherwise and the rescue team is in agreement. This SLR was unable to find a triage and treatment guideline or study examining this decision process, leaving the rescuers to base their decision to amputate or not on non-physiologic parameters. Certainly, if there is an imminent risk to the patient or the rescuers, an amputation must be performed to save the life of the patient and/or the rescuer(s). An absolute indication for amputation of the entrapped extremity is when there is immediate and real risk to the patient's life and those of the rescuers, when the scene is currently safe for the rescuers to enter, but the environment or the scene is deteriorating and time is of the essence.

This SLR was also unable to find a triage and treatment guideline or clinical study that examined whether clinical response to field therapy is factored into the decision to save a life over saving the limb. Although, it seems reasonable to seriously consider amputation of the entrapped extremity when the patient is physiologically unstable, when the patient is not responding to IV fluid (persisting hypotension), and/or there is the inability to maintain adequate oxygenation or other resuscitation measures due to occult blood loss or other injuries, and/or there is a lengthy extrication with perhaps greater than 6 hours total crush time (6 hours of ischemia). As a team with involvement of the patient (and their family if available), without reasonable scientific studies to provide a triage and treatment guideline, rescuers are left with the overriding question to answer before a field amputation, "Without the ability to extricate the patient, without performing a field amputation, will this patient surely die?"

The inconsistency in data reporting for physical exam findings, imaging, and operative findings may be a reflection of the specific research and/or a result of the lack of medical record keeping and falling below the accepted standard in the RRE in most countries. The authors accept that some studies were not specifically structured to incorporate physical examination findings and to wit the data extraction tool was limited to earmarking those studies. Data points were chosen to reflect those included in the many-mangled extremity scoring systems and, regardless of their validity or accuracy, these physical findings are pertinent in any environment to determine further evaluation and treatment.

Criteria from the WTA were incorporated into this study. The only step in the flow that would probably not be available in an RSE is a computed tomographic angiogram to provide imaging of the arterial injuries and reconstituted flow distal to the wound. The diagnostic resources available in an RSE triage and treatment guideline should consider that the RSE is without readily available computerized axial tomography scans, arteriography, and potentially without ultrasonography or plain X-rays even for a few patients, much less a mass casualty incident.

The key to extrapolating or adapting the imaging information used to guide the treatment of the mangled extremity from an RRE to an RSE is to understand the limitations or lack of imaging in the RSE ranging from scarce or unreliable electricity, equipment, and operators. After physician examination, arterial integrity is an important decision point and can be determined using a Doppler examination, or a handheld ultrasound probe using a smart phone, potentially available in an RSE. The use of scoring systems since 2002 has been shown to be useful to some extent but not to guide management as these guidelines imply. Therefore, future studies could investigate other modalities, such as ankle-brachial index and ultrasound, that were shown in this study.

Damage control surgery in the RSE can be modeled after the military environment where in-theater intravascular shunts have been shown to salvage the mangled extremity. ${ }^{60}$ Specific training and maintenance of competency of the general surgeon to perform this procedure in an RSE were shown to be effective, raising the potential for training of humanitarian surgeons in other RSEs. ${ }^{70}$

The WTA calls for classification of the bony injury that was not shown to be consistent in this SLR but can be made mandatory through education and a designed medical record that specifically records these parameters. Proper charting of the patient encounter with a mangled extremity, albeit curtailed after a mass casualty incident or in certain RSE, is to permit the treating physicians to be able to provide a more "comprehensive evaluation of systematic consequences of limb salvage attempt" when discussing treatment options with the patient, their family, or representative in the informed consent process. $^{3}$

The WTA algorithm's detail at the final stages of the limb salvage decision process was not found in the SLR. Certainly, one can offer that proper expedient decisions were made using a collaborative process involving the full treatment team, the patient, or their representatives to assure that the informed consent process was maintained and that after care was incorporated. But the standard in civilian, military, and most RREs is that the medical record details the history, physical exam, ancillary testing, as well as the discussions and future plans. This SLR did not encounter consistent documentation of this process.

Future triage and treatment guidelines should feature the patient's perspective from the earliest juncture in that patient's clinical course. International response teams working with the 
local government health authority and the WHO Global Health Cluster should work together to align triage and treatment guidelines with patient and family expectations.

Unfortunately, this may not have been the usual as reported in a follow-up study of amputees after the 2010 Haiti earthquake demonstrated that $79 \%$ would have preferred limb preservation. ${ }^{1}$ In their 2015 United Nations International Strategy for Disaster Reduction (UNISDR) Scientific and Technical Advisory Group case study, "Ethical dilemmas with amputations after earthquakes," O'Mathúna and von Schreeb succinctly described the challenges facing responders. ${ }^{71}$ This study confirmed the large number of ethical and clinical variables that must be in the evolving RSE physician calculus.

As future experts create triage and treatment guidelines of the entrapped and mangled extremity in the RSE, the consideration of the setting may be paramount to guide an algorithmic approach with appropriate staff, supplies, and structure to provide the means to the best possible clinical outcome. This may be because incidents that occur and are treated in remote, mobile facilities do not have these resources. The study of these settings may also lack for proper scientific data collection, further hindering application of triage and treatment guidelines in RSEs.

The treatment of an entrapped and mangled extremity in an RSE is a team effort with the depth of after-care planning initiated in concert with the technical aspects of the procedure to return the patient to the highest level of function and health. These data are encouraging because the majority of studies were published before the WHO Rehabilitation document. The informed consent process, present in civilian and military settings and advocated by the WHO and others, may be difficult in any emergent setting with provisions that meet jurisdiction, religious, and ethnic considerations to meet the standard for the patient to participate in their care.

The standard of care in an RSE remains paramount with the challenge to do the most good for the most people. Many supervisory, regulatory, and other GOs and non-GOs have produced anesthesia, analgesia, and antibiotic recommendations to treat the injured in the RSE to establish an expectation of care. Because some of the studies in the SLR were not specifically designed to examine use of medications, the data tool asked only whether classes of medications were discussed without delving into the specific indications or dosages of any medication. The authors were interested to learn whether recommendations were incorporated into clinical practice and reported accordingly.

\section{CONCLUSION}

The subject matter, triage, and treatment of the entrapped or mangled extremity in RSE were proven again to not lend itself to a formal PRISMA SLR that is designed for a more concrete treatment data analysis (eg, pharmacologic options) from more consistent environments (RRE) with more consistent documentation. Data captured can add to the body of available literature to convene the best scientific analysis to produce consensus clinical treatment guidelines through a Delphi process.

\section{About the Authors}

Research Center in Emergency and Disaster Medicine (CRIMEDIM), Università degli Studi del Piemonte Orientale, Novara, Italy (E. Weinstein, Ragazzoni, Franc, Verde); Department of Physical Medicine and Rehabilitation, Geisinger Health System, Bloomsburg, PA (Gosney); University of Alberta, Edmonton, AB (Franc); Library, Medical University of South Carolina, Charleston, SC (Herbert); PGY4 Plastic and Reconstructive Surgery, University of South Florida, Health Morsani College of Medicine, Tampa, FL (B. Weinstein); Department of Anesthesiology, Bundeswehr Central Hospital, Koblenz, Germany (Zeller); Department of Orthopedics, California Pacific Medical Center, Saint Francis Memorial Hospital, San Francisco, CA (Wolfson); MS4 Geisel School of Medicine, Dartmouth College, Hanover, NH (Boyce); and MS3 Medical University of South Carolina, Charleston, SC (Cramer).

Correspondence and reprint requests to Eric Weinstein, Research Center in Emergency and Disaster Medicine (CRIMEDIM), Università degli Studi del Piemonte Orientale, III Piano, Via Bernardino Lanino, 1, 28100 Novara NO, Italy (e-mail: eswein402@gmail.com).

\section{Acknowledgments}

We thank Professors Francesco Della Corte, Skip Burkle, Lisa Kurland, and Ahmadreza Djalali for their contributions to this study.

\section{Conflict of Interest Statement}

The authors have no conflicts of interest to declare.

\section{REFERENCES}

1. Feliciano D. Management of the mangled extremity 2002. Updated 2015. https://www.facs.org/ /media/files/qualityprograms/trauma/publications/ mangledextremity.ashx. Accessed July 7, 2015.

2. Schultz $\mathrm{CH}$, Annas GJ. Altering the standard of care in disasters unnecessary and dangerous. Ann Emerg Med. 2012;59(3):191-195.

3. Scalea TM, DuBose J, Moore EE, et al. Western Trauma Association critical decisions in trauma: management of the mangled extremity. J Trauma Acute Care Surg. 2012;72(1):86-93.

4. PRISMA. Prisma transparent reporting of systematic reviews and metaanalyses. 2015. http://www.prisma-statement.org. Accessed November 9, 2016.

5. Newhouse RP, Dearholt SL, Poe SS, et al. Johns Hopkins nursing evidencebased practice model and guidelines. Indianapolis: Sigma Theta Tau International; 2007.

6. The Ottawa Hospital. The Newcastle-Ottawa Scale (NOS) for assessing the quality of nonrandomized studies in meta-analyses. 2009. http:// www.ohri.ca/programs/clinical_epidemiology/oxford.htm. Accessed July 7, 2015.

7. The Cochrane Collaboration. Appendix F. Cochrane risk of bias tool, Cochrane handbook for systematic reviews of interventions, version 5.1.0. Updated March 2011. https://www.google.com/search?ei=6Qj OWs3SDcq6gge98bjYCg\&q=AUB+KQ1+Risk+of+Bias+Assessment \&oq $=$ AUB + KQ1 $1+$ Risk + of + Bias + Assessment \&gs_l=psy-ab.3 ...3015 186.3018935.0.3019851.30.25.0.0.0.0.253.2638.9j13j1.24.0...0...1c. 
1j2.64.psy-ab.22.7.868.6.0j0i67k1j0i22i30k1j0i22i10i30k1j35i39k1j0i 131i67k1j0i131k1.120.h2dgk-MNIvA. Accessed July 7, 2015.

8. Ly TV, Travison TG, Castillo RC, et al.; Leap Study Group. Ability of lower-extremity injury severity scores to predict functional outcome after limb salvage. J Bone Joint Surg Am. 2008;90(8):1738-1743.

9. Akula Maheswara M. A meta-analysis of amputation versus limb salvage in mangled lower limb injuries - the patient perspective. Injury. 2011; 42(11):1194-1197.

10. Bonanni F, Rhodes M, Lucke JF. The futility of predictive scoring of mangled lower extremities. J Trauma. 1993;34(1):99-104.

11. Bortolin M, Morelli I, Voskanyan A, et al. Earthquake-related orthopedic injuries in adult population: a systematic review. Prehosp Disaster Med. 2017;32(2):201-208.

12. Bosse MJ, MacKenzie EJ, Kellam JF, et al. A prospective evaluation of the clinical utility of the lower-extremity injury-severity scores. J Bone Joint Surg Am. 2001;83(1):3-14.

13. Bosse MJ, MacKenzie EJ, Kellam JF, et al. An analysis of outcomes of reconstruction or amputation of leg-threatening injuries. N Engl J Med. 2002;347(24):1924-1931.

14. Bosse MJ, McCarthy ML, Jones AL, et al. The insensate foot following severe lower extremity trauma: an indication for amputation? J Bone Joint Surg Am. 2005;87(12):2601-2608.

15. Brown KV, Ramasamy A, McLeod J, et al. Predicting the need for early amputation in ballistic mangled extremity injuries. J Trauma. 2009; 66(4 Suppl):S93-S97, discussion S7-S8.

16. Demiralp B, Ege T, Kose $O$, et al. Amputation versus functional reconstruction in the management of complex hind foot injuries caused by land-mine explosions: a long-term retrospective comparison. Eur J Orthop Surg Traumatol. 2014;24(4):621-626.

17. Ellington JK, Bosse MJ, Castillo RC, MacKenzie EJ; LEAP Study Group. The mangled foot and ankle: results from a 2-year prospective study. J Orthop Trauma. 2013;27(1):43-48.

18. Elsharawy MA. Arterial reconstruction after mangled extremity: injury severity scoring systems are not predictive of limb salvage. Vascular. 2005;13(2):114-119.

19. Essa AA, El-Shaboury IM, El-Beltagy YE. Evaluation of prognostic predictors of mangled extremity severity scoring system on the outcome of traumatic extremities injuries at emergency department in Suez Canal University Hospitals. Int Surg J. 2016;4(1):75.

20. Fagelman MF, Epps HR, Rang M. Mangled extremity severity score in children. J Pediatr Orthop. 2002;22(2):182-184.

21. Gifford SM, Aidinian G, Clouse WD, et al. Effect of temporary shunting on extremity vascular injury: an outcome analysis from the Global War on Terror vascular injury initiative. J Vasc Surg. 2009;50(3):549-555, discussion 55-56.

22. Helfet DL, Howey T, Sanders R, Johansen K. Limb salvage versus amputation. Preliminary results of the Mangled Extremity Severity Score. Clin Orthop Relat Res. 1990(256):80-86.

23. Khan F, Amatya B, Gosney J, et al. Medical rehabilitation in natural disasters: a review. Arch Phys Med Rehabil. 2015;96(9):28.

24. Loja MN, Sammann A, DuBose J, et al. The Mangled Extremity Score and amputation: time for a revision. J Trauma Acute Care Surg. 2017;82(3):518-523.

25. Lynch K, Johansen K. Can Doppler pressure measurement replace "exclusion" arteriography in the diagnosis of occult extremity arterial trauma? Ann Surg. 1991;214(6):737-741.

26. MacKenzie EJ, Bosse MJ, Kellam JF, et al. Factors influencing the decision to amputate or reconstruct after high-energy lower extremity trauma. J Trauma. 2002;52(4):641-649.

27. Madhuchandra P, Rafi M, Devadoss S, Devadoss A. Predictability of salvage and outcome of Gustilo and Anderson type-IIIA and type-IIIB open tibial fractures using Ganga Hospital Scoring system. Injury. 2015;46(2): 282-287.

28. Mills WJ, Barei DP, McNair P. The value of the ankle-brachial index for diagnosing arterial injury after knee dislocation: a prospective study. J Trauma. 2004;56(6):1261-1265.
29. Morelli I, Sabbadini MG, Bortolin M. Orthopedic injuries and their treatment in children during earthquakes: a systematic review. Prehosp Disaster Med. 2015;30(5):478-485.

30. Niles BL, Polizzi CP, Voelkel E, et al. Initiation, dropout, and outcome from evidence-based psychotherapies in a VA PTSD outpatient clinic. Psychol Serv. 2018;15(4):496-502.

31. Perkins ZB, Yet B, Glasgow S, et al. Meta-analysis of prognostic factors for amputation following surgical repair of lower extremity vascular trauma. $\mathrm{Br}$ J Surg. 2015;102(5):436-450.

32. Rajasekaran S, Naresh Babu J, Dheenadhayalan J, et al. A score for predicting salvage and outcome in Gustilo type-IIIA and type-IIIB open tibial fractures. J Bone Joint Surg Br. 2006;88(10):1351-1360.

33. Schiro GR, Sessa S, Piccioli A, Maccauro G. Primary amputation vs limb salvage in mangled extremity: a systematic review of the current scoring system. BMC Musculoskelet Disord. 2015;16:372.

34. Scott DJ, Watson JD, Heafner TA, et al. Validation of the Short Musculoskeletal Function Assessment in patients with battlefield-related extremity vascular injuries. J Vasc Surg. 2014;60(6):1620-1626.

35. Sharma S, Devgan A, Marya KM, Rathee N. Critical evaluation of mangled extremity severity scoring system in Indian patients. Injury. 2003;34(7):493-496.

36. Tekin L, Safaz Y, Goktepe AS, Yazycyodlu K. Comparison of quality of life and functionality in patients with traumatic unilateral below knee amputation and salvage surgery. Prosthet Orthot Int. 2009;33(1):17-24.

37. Tufescu TV. Mangled extremity. In: Bhandari M, ed. Evidence-Based Orthopedics. New York: Blackwell; 2011:655-660.

38. Agarwal V, Agarwal S, Singh A, et al. An evaluation of the clinical utility of mangled extremity severity score in severely injured lower limbs. Int $J$ Res Med Sci. 2016;4(5):1661-1665.

39. Akpoto YM, Abalo A, Adam S, et al. Extremity injuries in soldiers during the conflict in Mali: experience of Togo level two hospital. Int Orthop. 2015;39(10):1895-1899.

40. Bartels SA, Van Rooyen MJ. Medical complications associated with earthquakes. Lancet. 2012;379(9817):748-757.

41. Behdad S, Rafiei MH, Taheri H, et al. Evaluation of Mangled Extremity Severity Score (MESS) as a predictor of lower limb amputation in children with trauma. Eur J Pediatr Surg. 2012;22(6):465-469.

42. Brown KV, Murray CK, Clasper JC. Infectious complications of combatrelated mangled extremity injuries in the British military. J Trauma. 2010;69(Suppl 1):S109-S115.

43. Burkhardt GE, Cox M, Clouse WD, et al. Outcomes of selective tibial artery repair following combat-related extremity injury. J Vasc Surg. 2010;52(1):91-96.

44. Dagum AB, Best AK, Schemitsch EH, et al. Salvage after severe lowerextremity trauma - are the outcomes worth the means? Plast Reconstr Surg. 1999;103(4):1212-1220.

45. De Freitas Valeiro Garcia D, de Sá RRC, de Oliveira Bernini C, Rasslan S. Preliminary results of a prospective study on severe lower limb trauma: analysis of laboratory tests as predictors of amputation. Panam J Trauma Crit Care Emerg Surg. 2013;2(1):58-61.

46. De Silva WDD, Ubayasiri RA, Weerasinghe CW, Wijeyaratne SM. Challenges in the management of extremity vascular injuries: a wartime experience from a tertiary centre in Sri Lanka. World J Emerg Surg. 2011;6(1):24.

47. Delauche MC, Blackwell N, Le Perff $\mathrm{H}$, et al. A prospective study of the outcome of patients with limb trauma following the Haitian earthquake in 2010 at one- and two- year (The SuTra2 Study). PLoS Curr. 2013;5:epub.

48. Doucet JJ, Galarneau MR, Potenza BM, et al. Combat versus civilian open tibia fractures: the effect of blast mechanism on limb salvage. J Trauma. 2011;70(5):1241-1247.

49. Ege T, Unlu A, Tas H, et al. Reliability of the mangled extremity severity score in combat-related upper and lower extremity injuries. Ind J Orthop. 2015;49(6):656-660.

50. Fortuna G. Contemporary outcomes of lower extremity vascular repairs extending below the knee: a multicenter retrospective study. J Trauma Acute Care Surg. 2016;81(1):63-70. 
51. Gerdin M, Wladis A, von Schreeb J. Surgical management of closed crush injury- induced compartment syndrome after earthquakes in resourcescarce settings. J Trauma Acute Care Surg. 2012;73(3):758-764.

52. Harris MA, Althausen PL, Kellam JF, et al.; The LEAP Study Group. Complications following limb-threatening lower extremity trauma. J Orthop Trauma. 2009;23(1):1-6.

53. Hossny A. Blunt popliteal artery injury with complete lower limb ischemia: is routine use of temporary intraluminal arterial shunt justified? $J$ Vasc Surg. 2004;40(1):61-66.

54. Johansen K, Daines M, Howey $\mathrm{T}$, et al. Objective criteria accurately predict amputation following lower extremity trauma. J Trauma. 1990;30(5):568-572, discussion 72-73.

55. Kauvar DS, Sarfati MR, Kraiss LW. National trauma databank analysis of mortality and limb loss in isolated lower extremity vascular trauma. J Vasc Surg. 2011;53(6):1598-1603.

56. O'Sullivan ST, O'Sullivan M, Pasha N, et al. Is it possible to predict limb viability in complex Gustilo IIIB and IIIC tibial fractures? A comparison of two predictive indices. Injury. 1997;28(9-10):639-642.

57. Redmond AD, Mardel S, Taithe B, et al. A qualitative and quantitative study of the surgical and rehabilitation response to the earthquake in Haiti, January 2010. Prehosp Disaster Med. 2011;26(6):449-456.

58. Sheean AJ, Krueger CA, Napierala MA, et al. Evaluation of the mangled extremity severity score in combat-related type III open tibia fracture. J Orthop Trauma. 2014;28(9):523-526.

59. Sisli E, Kavala AA, Mavi M, et al. Single centre experience of combatrelated vascular injury in victims of Syrian conflict: retrospective evaluation of risk factors associated with amputation. Injury. 2016;47(9): 1945-1950.

60. Taller J, Kamdar JP, Greene JA, et al. Temporary vascular shunts as initial treatment of proximal extremity vascular injuries during combat operations: the new standard of care at Echelon II facilities? J Trauma. 2008;65(3):595-603.

61. Williams ZF, Bools LM, Adams A, et al. Early versus delayed amputation in the setting of severe lower extremity trauma. Am Surgeon. 2015;81(6): 564-568.
62. Wuthisuthimethawee P, Lindquist SJ, Sandler N, et al. Wound management in disaster settings. World J Surg. 2015;39(4):842-853.

63. Yavuz C, Demirtas S, Caliskan A, et al. The predictors of poor outcomes in patients with femoral artery injuries. Eur Rev Med Pharmacol Sci. 2013;17(14):1901-1908.

64. Yeh HK, Fang F, Lin YT, et al. The effect of systemic injury score on the decision making of mangled lower extremities. Injury. 2016;47(10): 2127-2130.

65. Jensen G, Bar-On E, Wiedler JT, et al. Improving management of limb injuries in disasters and conflicts. Prehosp Disaster Med. 2019;34(3): 330-334.

66. Ladlow P, Philip R, Coppack R, et al. Influence of immediate and delayed lower-limb amputation compared with lower-limb salvage on functional and mental health outcomes post-rehabilitation in the U.K. military. J Bone Joint Surg Am. 2016;98:17.

67. WHO. Minimum technical standards and recommendations for rehabilitation. Geneva: WHO. 2016. https://extranet.who.int/emt/sites/default/ files/MINIMUM TECHNICALSTANDARDS.pdf?ua=1. Accessed July 17, 2017.

68. Norton I, von Schreeb J, Aitken P, et al. Classification and minimum standards for foreign medical teams in sudden onset disasters, 2013. Updated 2013. https://www.who.int/hac/global_health_cluster/fmt_guidelines_ september2013.pdf?ua=1. Accessed April 15, 2015.

69. WHO. Management of limb injuries during disasters and conflicts, 2016. Updated 2016. https://icrc.aoeducation.org/files/downloads/A_Field_ Guide_Low_res.pdf.. Accessed November 26, 2016.

70. Wong EG, Trelles M, Dominguez L, et al. Surgical skills needed for humanitarian missions in resource-limited settings: common operative procedures performed at Médecins Sans Frontières facilities. Surgery. 2014;156(3):642-649.

71. O'Mathuna DP, von Schreeb J. UNISDR Scientific and Technical Advisory Group case studies - 2015 Ethical dilemmas with amputations after earthquakes, 2015. Updated 2015. https://www.preventionweb. net/files/workspace/7935_omathunaamputation.pdf. Accessed June 6, 2015. 